\title{
Inserção profissional na docência: experiência de egressos do PIBID
}

\author{
Isabel Maria Sabino de Farias ${ }^{1}$ \\ ORCID: 0000-0003-1799-0963 \\ Silvina Pimentel Silva ${ }^{1}$ \\ ORCID: 0000-0002-5486-3608 \\ Nilson de Souza Cardoso ${ }^{1}$ \\ ORCID: 0000-0003-3214-8942
}

\section{Resumo}

Discute sobre a formação de professores egressos de programa de iniciação à docência em seus primeiros anos de inserção no magistério. Parte-se do argumento de que, em geral, professores mais amplamente preparados e certificados são mais bem-sucedidos na tarefa de ensinar, instigando questionamentos sobre como docentes iniciantes, egressos de oportunidades diferenciadas de aprendizagem durante a formação inicial, vivenciam os primeiros anos de magistério. A análise recorre a dados sobre inserção profissional de egressos de programas de iniciação à docência, precisamente do Programa Institucional de Bolsa de Iniciação à Docência (PIBID) no Ceará. A metodologia envolveu a realização de uma pesquisa de levantamento com 263 egressos do PIBID de duas Instituições de Ensino Superior (IES) cearenses. São jovens adultos com socialização pré-profissional, com aprendizagens constituídas em trajetória de escolarização marcada por experiência curricular na rede pública. 0 efetivo exercício da docência predomina entre os investigados (75,6\%). A participação no PIBID proporcionou aos egressos deste ensaio, durante a formação inicial e a inserção na carreira, um defrontar-se mais construtivo em relação aos dilemas do ofício, fornecendo elementos para se reconhecerem capazes de enfrentar desafios. Predomina entre eles intensa identificação com o magistério, exceto por um reduzido grupo, que descobre, com essa experiência e a vivência dos primeiros anos de docência, que prefere investir esforços em uma profissão que lhe garanta retorno mais vantajoso. Mesmo ante as adversidades inerentes às demandas do trabalho, eles se declaram mais bem preparados para encarar os dilemas dos primeiros anos de magistério.

\section{Palavras-chave}

Inserção profissional - Professores iniciantes - Pibid - Formação de professores.

1- Universidade Estadual do Ceará, Fortaleza, CE - Brasil.

Contatos: isabelinhasabino@yahoo.com.br; silvina.pimentel@uece.br; nilson.cardoso@uece.br

https://doi.org/10.1590/S1678-4634202147225968

This content is licensed under a Creative Commons attribution-type BY-NC. 


\title{
Professional integration in teaching: the experience of former PIBID students*
}

\begin{abstract}
We discuss teacher training of former students of a teaching initiation program in their first years of professional integration. We begin with the assertion that, generally, teachers who are more broadly prepared and certified are more successful in teaching, instigating questions about how beginner teachers, from differentiated learning opportunities during initial training, experience the first years of teaching. The analysis turns to facts about the professional integration of former students of teaching initiation programs, specifically from the Institutional Program of Initiation to Teaching Scholarship (PIBID, in Portuguese) in Ceará. Methodology involved carrying out a survey with 263 former members of PIBID from two Higher Education Institutions (HEI) in Ceará. They are young adults with prevocational socialization, whose learning took place in a school trajectory marked by curricular experience in the public network. Effective teaching practice prevails among those surveyed (75.6\%). Participating in PIBID allowed future teachers in this study, during initial training and professional integration, to face the profession's dilemmas more constructively, providing elements to recognize themselves as capable to endure challenges. Among them prevails a strong identification with teaching, except for a small group, who discover, with that experience and their first years in the profession, that they prefer to invest their effort into a profession that will grant them more advantages. Even in the face of adversities inherent to the demands of the career, they acknowledge being more prepared to confront the dilemmas in the first years of teaching.
\end{abstract}

\section{Keywords}

Professional integration - Beginner teachers - PIBID - Teacher training.

\section{Introdução}

Discutir sobre formação de professores é a proposição deste artigo, precisamente, de professores egressos de programa de apoio de iniciação à docência em seus primeiros anos de inserção no magistério. Este tema se exprime como portador de muitas preocupações, necessitando ainda de enveredarmos na busca de respostas para melhor esclarecer o entendimento de indagações que envolvem a emblemática formação de professores. Destas, fazem parte as que intentam saber: ter mais formação e, sobretudo, uma formação mais próxima do futuro local de trabalho, favorece a atuação docente, em particular daqueles que estão iniciando o exercício da profissão?

Darling-Hammond (2014, p. 231) argumenta, com base na revisão de estudos da área, que, a despeito das lacunas nesse âmbito, são justamente os docentes mais "amplamente 
preparados e certificados" os que "[...] obtêm, em geral, melhores resultados e são mais bem-sucedidos com os alunos do que os professores sem esse tipo de preparação".

Os estudos nesta seara, no contexto brasileiro, estimulam questionamentos sobre egressos de cursos de licenciatura que participaram de oportunidades diferenciadas de aprendizagem durante a formação inicial para a docência, pressupondo que esses sejam portadores de subsídios mais consistentes para lidarem com maior competência em aspectos que envolvem o ensino e a aprendizagem.

Nesses termos, cabe reconhecer a responsabilidade dos processos formativos no preparo dos docentes para que possam exercer com a necessária competência as tarefas demandadas pela prática pedagógica na realização de sua ação docente. Este fato nos convida a compreender que as aprendizagens decorrentes da natureza dos conteúdos ensinados e assimilados, bem como das experiências vivenciadas no decurso de seu desenvolvimento pessoal e profissional, os diferenciam como professores. Esses pressupostos nos remetem a problematizar se graduandos que participam de programas envolvendo ações de iniciação à docência têm uma formação distinta dos demais graduandos que não acessaram experiências dessa natureza.

As preocupações das pesquisas em torno dessas discussões são alargadas, extrapolando e evoluindo em relação ao que seja "aprender a ensinar", indo na "[...] direção da indagação sobre os processos pelos quais os professores geram conhecimento" e também de saber "quais os tipos de conhecimentos adquirem". (MARCEL0, 1998, p. 51). Tal movimento nos incita a perquirir sobre como se desenvolvem professores iniciantes em circunstância de inserção profissional e com quem aprendem.

A ideia de inserção profissional docente é aqui compreendida como período que demarca os primeiros anos do docente em um novo contexto de exercício profissional, perpassado por tensões geradas pela necessidade de atuar e de se afirmar em um ambiente desconhecido, interferindo em sua socialização profissional (CRUZ, 2018). Professores em situação de inserção profissional, sejam experientes ou iniciantes na docência, confrontam-se com a nova realidade de trabalho (ALARCÃO; ROLDÃo, 2014), vivenciam dúvidas e demandas com as quais precisam aprender a lidar. Em sendo assim, a ideia de entrada em um contexto de trabalho até então desconhecido é central ao conceito de inserção profissional.

Embora a entrada na profissão seja uma deliberação privada do professor, este é um momento do seu ciclo de vida profissional decisivo na permanência e na sua relação com a docência, sobretudo para aqueles em início de carreira (com até cinco anos de docência), foco desta análise. Decisivo porque, como adverte Mizukami (2013, p. 23), “[...] a docência é uma profissão complexa e, tal como as demais profissões, é aprendida. Os processos de aprender a ensinar, de aprender a ser professor e de se desenvolver profissionalmente são lentos”. Para o professor iniciante, a inserção é ainda mais delicada e desafiante, pois ele vivencia um tempo de transição de estudante a professor (GARCÍA, 1999; TARDIF, 2014) e de "choque com a realidade", experimentando sentimentos de sobrevivência e descobertas. Tudo isso tensiona o profissional iniciante, mas, ao mesmo tempo, propicia aprendizagens intensivas sobre a prática do seu mister. 
Com esteio nessas perquisições, este escrito tem como intento discutir sobre professores em seus primeiros anos de inserção no magistério, egressos de um programa de apoio à iniciação à docência e, mais precisamente, dirigimos a atenção para docentes iniciantes egressos do PIBID no Ceará.

\section{A pesquisa² que alimenta nossas análises: aspectos metodológicos}

Os questionamentos que movem este exame são oriundos de indicadores de investigação ampla, apoiada pelo $\mathrm{CNPq}$, sobre inserção profissional de egressos de programas de iniciação à docência no Brasil ${ }^{3}$ - o Residência Pedagógica, o Bolsa Alfabetização e o Programa Institucional de Bolsa de Iniciação à Docência (PIBID). É nessa última ação, precisamente em dados do PIBID no Ceará, de egressos de duas IES públicas cearenses, entre os anos 2009 e 2013, que encontramos os elementos empíricos para embasar as análises qualitativas (STAKE, 2011; ANDRÉ, 1983) que ancoram este texto.

Esta investigação ampla, cabe esclarecer, em sua primeira fase, realizou uma pesquisa de levantamento (YIN, 2016) junto a egressos das três iniciativas supra citadas, com suporte de questionários virtuais de autopreenchimento na plataforma SurveyMonkey, cujo intento era atingir um grande número de participantes buscando elementos sobre a relação entre a participação nos programas de iniciação a docência e o ingresso na profissão. Os instrumentais possuíam questões de múltipla escolha (19) ou com escala tipo Likert (18) e ainda, perguntas abertas para livre manifestação (02). A aplicação perdurou os meses de fevereiro e abril de 2016, contemplando dados de nove diferentes Estados brasileiros. Foram feitas duas campanhas de esclarecimentos sobre o escopo e objetivos da investigação, sensibilizando para a adesão, envolvendo a colaboração de coordenadores dos programas, com vista à ampla participação dos egressos.

Desse conjunto, no Ceará, participaram duas instituições públicas de ensino superior (IPES): uma federal (IPES1) e uma estadual (IPES2). Ao todo, considerando-se egressos do primeiro ciclo do PIBID no Estado (2009-2013) e que concluíram a formação inicial em 2013 ou 2014, foram enviados os questionários virtuais a 861 endereços eletrônicos válidos de ex-bolsistas (582 da IPES1; 279 da IPES2), embora com o retorno de somente 263 egressos (166 da IPES1; 97 da IPES2).

Neste escrito, a análise centra-se nos resultados dessas duas instituições, referentes aos egressos do Programa PIBID naquele período, no Estado. Nas seções a seguir, suas respostas compõem as apreciações desta discussão.

2- 0 desenvolvimento da investigação de onde se obteve os dados analisados nesse escrito observou os procedimentos éticos estabelecidos para a pesquisa científica, cujo parecer de aprovação no Comitê de Ética em Pesquisa (CEP) está inscrito sob o nº 1.735.857, na Plataforma Brasil. 3- Os programas citados, excluindo-se o PIBID, são de atuação exclusiva no Estado de São Paulo, sendo o Residência Pedagógica uma iniciativa originada na Universidade Federal de São Paulo (Unifesp) e o Bolsa Alfabetização promovido pela Secretaria de Educação do Estado de São Paulo.

4- http://www.surveymonkey.com 


\section{Quem são os egressos do PIBID que participaram deste estudo?}

É pertinente ressalvar que o PIBID é um programa de caráter complementar, vinculado à Diretoria de Educação Básica Presencial (DEB) da Coordenação de Aperfeiçoamento de Pessoal de Nível Superior (CAPES), que “[...] tem por finalidade de fomentar a iniciação à docência, contribuindo para o aperfeiçoamento da formação de docentes em nível superior e para a melhoria da qualidade da educação básica pública brasileira”. (BRASIL, 2010, p. 4). Um dos seus objetivos descansa em propiciar a inserção de alunos de licenciatura no contexto da rede pública de ensino, desde o início de sua formação acadêmica. A eles são concedidas bolsas de iniciação à docência, para que desenvolvam atividades didáticopedagógicas, orientados e acompanhados por docentes de instituições de ensino superior (IES) integrantes do programa, em parceria com escolas de educação básica.

0 Ceará participa do PIBID desde sua primeira edição, em 2007, quando a IPES1 coordenou seis subprojetos. A IPES2 se insere em 2009, momento em que a possibilidade de participação das instituições de ensino superior no programa é ampliada, não se restringindo apenas às instituições federais. Nos editais subsequentes, o Estado registrou movimento ascendente na participação das IES cearenses nessa iniciativa (FARIAS; JARDILINO; SILVESTRE, 2015) que, nesse contexto, e a exemplo do que se registra nacionalmente, é reconhecida por gestores escolares, professores e estudantes como uma ação distintiva e qualificadora da formação de futuros professores (ANDRÉ, 2018).

Os elementos delineados a seguir possibilitam compor um retrato dos egressos do PIBID nesta unidade da Federação, o qual ajuda a compreender sua relação com a inserção profissional desses sujeitos na docência.

No Ceará, os egressos da IPES1 e da IPES2, relativamente ao primeiro ciclo do PIBID no Estado, expressam faixa etária predominante de 24 a 39 anos, portanto, representam um grupo de jovens adultos. Na primeira instituição não há egressos que assumam ter 50 anos ou mais e, na segunda, apenas um situou-se nesta idade. São jovens adultos oriundos de dez cursos de licenciatura - artes, ciências biológicas, educação física, geografia, física, história, letras, matemática, pedagogia e química. Somente na IPES1 aparecem egressos do PIBID na área de artes. A distribuição dos egressos que responderam ao questionário em relação às licenciaturas cursadas é relativamente equilibrada, tanto entre os cursos como comparativamente entre as instituições. São egressos que concluíram há menos de cinco anos a formação inicial, com maior incidência no ano de 2014 - movimento manifesto tanto na IPES1 $(57,83 \%=96)$ quanto na IPES2 $(59,79 \%=58)$.

Os participantes deste estudo incluem na contextura de sua formação uma estreita relação com o cotidiano do ensino público, evidenciando uma socialização préprofissional marcada por aprendizagens, constituídas por suas trajetórias de escolarização sob intensiva influência da prática curricular no contexto da escola pública entre esse grupo de licenciados, pois 159 (60,46\%) dos 263 participantes informaram ter cursado o ensino fundamental todo em escola pública, isso sem considerar os declarantes de que nela fizeram a maior parte de seus estudos e dos que afiançaram ter nela cursado metade de sua escolarização. Esta trajetória, na qual estiveram "expostos a um maior período de 
observação não dirigida em relação às funções e tarefas que desempenharão no futuro" (MARCELO, 2009, p. 116), é constitutiva de suas identidades profissionais.

Esse movimento, de maneira geral, se mantém em relação ao Ensino Médio, embora possamos observar uma leve variação no percentual de egressos procedentes da escola pública $(41,4 \%=109)$ em relação àqueles que o realizaram em instituições de ensino particulares $(31,9 \%=84)$. Nessa etapa da escolarização, chama atenção o tipo de curso buscado pelos egressos do PIBID: o ensino médio regular, chegando, em ambas as instituições, à casa dos 93\%. Cursos profissionalizantes, técnicos (eletrônica, contabilidade, agrícola, etc.) e magistério (curso normal) são mais ocorrentes entre os formandos da IPES2, o que é compatível com o perfil do alunado atendido por essa instituição, em geral, advindos de estratos sociais com maior premência de inserção no mundo do trabalho.

A expectativa suscitada é de que o currículo da escola pública seja o que exerce maior influência em relação aos aprendizados pré-profissionais adquiridos pelos professores iniciantes egressos do PIBID, respondentes da pesquisa. Ainda sobre os aprendizados profissionais, Marcelo (2009, p. 117) acrescenta que a "experiência com o conhecimento formal", realizado no contexto de trabalho, contribui para a compreensão do modo de ensinar e aprender. Destaca também que essa experiência da prática docente em contexto de atuação, neste caso como aprendizagem durante a formação inicial, pode ser caminho para superar a existência do "mito" que é a prática que realmente forma o professor, em detrimento das discussões da teoria, favorecendo uma dicotomia (GARCÍA, 1999, p. 95).

Os dados examinados permitem-nos dizer, ainda, que os egressos do PIBID em foco nessa análise são jovens adultos que, mais acentuadamente, desde sua entrada no ensino superior, investem em sua formação, declarando que, desde sua admissão à universidade buscam oportunidades que envolvam o tripé ensino, pesquisa e extensão. Esse é um percurso promissor, sobretudo em face do argumento de que as "experiências adquiridas enquanto aluno" e as "imagens que transporta dos professores que viu atuar" (FORMOSINHO; MACHADO, 2009, p. 145) trazem para a formação docente "um modelo de comportamento profissional" a seguir ou a rejeitar. Evidencia-se entre os egressos que responderam à pesquisa de levantamento o reconhecimento, desde a formação inicial, da docência como atividade profissional cujo conhecimento reclama aprendizagens diversificadas e contínuas.

\section{Relação com a docência dos egressos do PIBID}

Em atenção ao cuidado com uma formação mais bem qualificada, podemos identificar o interesse que os respondentes deste estudo demonstram em participar de espaços diversos de formação e que favoreçam a formulação de conhecimentos que os ajudem a enfrentar as dificuldades que aportam à ação docente cotidianamente. A relação ensino e pesquisa faz parte de suas declarações, bem como nas inquietações manifestas sobre o que podemos denominar de "formação para além do ensino" (FARIAS et al., 2014), ainda que de maneira muito rudimentar ou incipiente.

Esse registro se configura na anotação da participação, no decurso da formação inicial, em diversas atividades acadêmicas, deixando transparecer uma inquietação em 
ampliar e fortalecer ou diversificar seu aprendizado profissional. A busca pela formação em pesquisa prevaleceu, considerando-se que assinalam ter vivenciado atividades de iniciação científica (85) e ações em projetos de pesquisa conduzidos por docentes da instituição (102). Monitoria (84) e experiências extensionistas (89) também receberam significativa indicação. As falas dos egressos do PIBID sinalizam para o reconhecimento da indissociabilidade teoria-prática, o que evidencia o entendimento de que as atividades de ensino devam ser retroalimentadas por novos conhecimentos, constantemente. Como ensina Freire (2007, p. 32), “[...] Enquanto ensino, continuo buscando, reprocurando”.

0 efetivo exercício da docência se sobressai como a função predominante entre os investigados. Dos 263 egressos do PIBID, um grupo de 199 (75,6\%) declarou que se encontra atuando na área da educação, com ênfase na docência. As funções de coordenação pedagógica e gestão aparecem de modo bastante discreto, assim como o exercício de "outras funções", como as de agente administrativo, técnico de secretaria de educação, mediador de projeto de leitura, responsável por ministrar cursos e monitoria escolar. Este é um dado relevante, pois torna evidente o estímulo produzido, desde a participação nesse programa, para o ingresso na docência após a conclusão da licenciatura, de um contingente representativo que atua em escolas.

Ademais, o exame das razões aludidas pelos que declararam não estar atuando na área, também, tende a reforçar o PIBID como iniciativa que incita a opção pelo magistério. Isso porque as justificativas explicitadas pelos egressos pendem para realçar elementos que evidenciam a busca por uma entrada na carreira em condições mais favoráveis, uma vez que a referência à continuidade dos estudos se sobreleva às demais motivações, as quais aludem ao aguardo para ingresso por concurso público, embora apontem a ausência de oportunidades e de condições como provocativa da pouca atratividade pela carreira do magistério, o que os impulsiona para a atuação em outras áreas.

0 tema da atratividade da carreira do magistério é objeto de reflexão de vários autores, entre eles Gatti (2009), ao advertir sobre sua instabilidade e descontinuidade no atual momento histórico, por conseguinte, sobre os desafios, incertezas e a exigência cada vez maior de novos investimentos. Ao que parece, os egressos do PIBID que declararam não estarem atuando na área confrontam-se com essa realidade e a enfrentam buscando o aprimoramento (os que estão estudando, fazendo especialização e/ou mestrado) ou uma modalidade de inserção menos instável (os aprovados por concurso público), movimento que, de certo modo, denota configurar um grupo com expectativas mais claras em relação à carreira e cuja escolha talvez venha sendo estabelecida de maneira mais deliberada (VALLE, 2006; CAVALCANTE, 2018).

Sobremodo, os professores iniciantes desse grupo, e que responderam à pesquisa de levantamento, atuam expressivamente no ensino fundamental e médio, seguido da educação infantil e da chamada modalidade única (Educação de Jovens e Adultos - EJA). A atuação em uma única escola é bem representativa, situada na casa dos 85,2\% nos oriundos da IPES2 e 64,3\% da IPES1. À primeira vista, o dado pode sugerir uma dedicação e uma condição de trabalho favorável, impressão que se dissipa ao articulá-lo com a carga horária de trabalho declarada, concentrada no intervalo entre 10 e 30 horas-aulas. Este movimento é compativel com o fato de serem recém-graduados, e a faixa etária 
dos egressos sugere que um contingente significativo deles busca uma inserção inicial na docência que também lhes assegure um tempo livre, o que pode estar relacionado à preocupação com investir nos estudos (maior qualificação e preparação para concurso) para, assim, alcançarem uma situação de trabalho mais vantajosa.

Essa possibilidade aufere vigor, se considerada a atual circunstância de trabalho por eles informada, ou seja, marcada pelo contrato temporário (78,5\% na IPES2 e 53,1\% na IPES1). A condição de docente transitório reporta-se à prática de contratação de professores por tempo determinado, que é cunhada por um vazio de direitos ${ }^{5}$. Na rede estadual cearense, indicativos da Secretaria de Planejamento do Estado do Ceará (SEPLAG), de 2014, mostram que, "[...] dos professores ativos, 47,4\% são servidores e 52,5\% temporários”, o que significa, em números absolutos, respectivamente, 17.694 professores efetivos e 19.633 temporários (APRECE, 2015, p. 3). A situação da rede municipal de Fortaleza se distancia desse modelo. Na Capital, por exemplo, dados de 2016 disponibilizados pela sua Secretaria Municipal de Educação (SME) indicam a existência de 12.515 professores, dos quais $9.656(77,15 \%)$ são efetivos e 2.859 (22,8\%) substitutos (de contrato precário).

Na contramão de alguns argumentos sobre a evasão para a rede privada ou mesmo da docência, os professores iniciantes egressos desse programa no Ceará destacam a rede pública de ensino - estadual, municipal e federal - como terreno institucional predominante de atuação. A constatação evidencia a necessidade de investimentos que favoreçam a permanência na carreira, especialmente iniciativas de apoio nos anos iniciais do exercício docente, conforme ponderam García (1999), André (2012), Nono e Mizukami (2006).

Os subsídios examinados trazem expectativas positivas sobre a relação dos egressos do PIBID no Ceará, ao revelarem robusta aderência ao exercício docente, com a concentração na rede pública. 0 PIBID parece, ao menos em relação a esse grupo, ter alcançado êxito em seu propósito de estimular a opção pelo magistério. A incorporação desses profissionais à rede pública de ensino, porém, dirige-se a situá-los em um estado de trabalho vulnerável, o que, decerto, tem consequências sobre o modo como vivem seus primeiros anos na docência.

\section{Perspectivas dos professores iniciantes egressos do PIBID sobre o início da docência}

Os estudos acerca da entrada no magistério pressupõem que não se nasce professor, aprende-se a ser docente; por conseguinte, destacam o contexto de trabalho, as relações ali vividas, como primordiais nessa aprendizagem e no desenvolvimento do ser professor. Como assevera Cavaco,

\footnotetext{
5- Noutras palavras, não possui nenhum tipo de vínculo empregatício com o Poder Público que o contrata. Vínculo precário porque, entre outros agravos, o contrato pode expirar ou ser rescindido sem direito a indenização, a exemplo de seguro-desemprego. 0 período de duração máxima do contrato é de 12 meses, o que expõe o docente a uma situação de incerteza quanto à renovação ou não de seu contrato no período subsequente. Ademais, o professor temporário não tem direito ao "Plano de Cargos, Carreiras e Salários" da categoria, recebendo aquém dos demais colegas, não importando sua titulação ou tempo de serviço.
} 
[...] aprende-se através da prática profissional, na interação com os outros (os diversos outros: alunos, colegas, especialistas, etc.) enfrentando e resolvendo problemas, apreciando criticamente o que se faz e como se faz, reajustando as formas de ver e agir. (CAVAC0, 1991, p. 167).

Neste sentido, o estudo procurou conhecer a perspectiva dos 199 professores iniciantes cearenses egressos do PIBID sobre o início do exercício na docência, considerando as seguintes temáticas: a) apoio e reconhecimento; b) ambiente de trabalho; c) gestão da aula; d) infraestrutura e recursos; e) condições de trabalho e salário; e f) contribuição do programa de iniciação à docência.

0 apoio e reconhecimento no início da docência foi considerado em relação ao grupo gestor, os professores veteranos, os pais dos alunos e ao acompanhamento da equipe pedagógica da escola. De modo geral, os dados revelam que os professores iniciantes se acham reconhecidos e apoiados por esses quatro segmentos, muito embora esse sentimento seja menos incisivo em relação aos pais dos alunos e à equipe pedagógica. A busca de apoio fora da escola aparece de modo proeminente como estratégia para se fortalecer e enfrentar o cotidiano da docência na escola, o que corrobora as análises de Cavaco (1991). A autora portuguesa esclarece que, "[...] estas redes informacionais, de troca de experiência e partilha de conhecimentos, podem constituir principalmente sistemas consolidadores de rotinas”, cujo principal resultado é mais afastar a insegurança e a ansiedade que os iniciantes encaram no seu dia a dia "[...] do que assegurar um dispositivo facilitador da formação profissional”. (CAVAC0, p. 167).

Quanto ao ambiente de trabalho, prevalece entre os iniciantes a identificação de um clima de trabalho agradável nos contextos em que se encontram inseridos, a considerar as concordâncias completas e parciais. Sentimento semelhante pode ser percebido ao se referirem à discussão da prática com os outros colegas. 0 depoimento que segue é representativo da sensação de apoio e acolhida reportada pelos docentes participantes da pesquisa:

Quando adentrei pela primeira vez em sala de aula fiquei bastante assustada, pois agora era só eu e os meus alunos. Como devo proceder? Por que antes era bolsista e não ficava só com as crianças e, por conta disso, pensei em desistir, mas comentei essa insatisfação com alguns professores e eles me confortaram dizendo que era assim mesmo, mas que depois veria que era apenas nervosismo por conta do novo. (Professor Iniciante A).

Embora assim tenham se posicionado, contudo, os iniciantes revelaram também que sentem resistência da escola ante as distintas práticas pedagógicas, percepção assim manifesta em um dos registros analisados:

Há dificuldade na aceitação dos professores efetivos e veteranos, para com o reconhecimento das diferentes práticas de professores temporários e novatos, principalmente uma desvalorização dos docentes jovens, com uma prática diferenciada. Acaba que os mais antigos "debocham" e não os respeitam. (Professor Iniciante B).

Apesar de se discutir muito sobre novas práticas pedagógicas, muitas vezes, a própria escola não aceita propostas inovadoras. (Professor Iniciante C). 
A resistência aludida pode ser compreendida como sintomática da desconfiança em relação ao novo e das expectativas de mudança que este traz para as crenças e práticas já constituídas (FARIAS, 2006), por conseguinte, para a cultura pedagógica da escola.

Embora façam esse registro, esses professores iniciantes parecem satisfeitos com o resultado de sua atuação em sala de aula, tanto no que se refere à aprendizagem dos alunos quanto à vivência de experiências positivas na gestão da sala de aula, conforme indicam as concordâncias completas e parciais a esses aspectos. É o que reforça a anotação a seguir: "No início não foi tão fácil preparar as aulas e mostrar para os alunos o quanto a ciência química é interessante. Com o passar do tempo eles foram compreendendo a importância dessa ciência nas nossas vidas" (Professor Iniciante D). Saber-se capaz de dar conta do trabalho de ensinar, de mediar a aprendizagem dos alunos, de conduzir as interações sociocognitivas e afetivas no contexto da sala de aula, é um dos desafios que tencionam os primeiros anos da docência, pois significa, em última instância, se firmar como professor, ultrapassando a condição de estudante (TARDIF, 2014).

As contradições e desafios que marcam o início da docência são agravados, ainda, pelas modalidades da distribuição de trabalho prevalecente na escola, a exemplo da designação das turmas mais difíceis para os professores iniciantes, conforme assinalam diversos autores. Nota-se, porém, que, entre esses iniciantes egressos do PIBID no Ceará, essa é uma prática em movimento, uma vez que se observa certo equilíbrio entre as respostas assinalando concordância (completa e parcial) com a afırmação de que receberam as turmas mais difíceis da escola e aquelas que indicam discordância (completa e parcial). Esta evidência parece sinalizar a existência, mesmo que emergente, de um cuidado com o iniciante, um reconhecimento de sua fragilidade e do momento delicado de sua trajetória profissional, principalmente em face dos desafios da gestão da aula.

A gestão da aula e tudo o que a envolve exprimem-se como um "batismo de fogo" para o iniciante, pois é no contexto da aula que as dificuldades que intervêm sobre a ação de ensinar se sobressaem, a exemplo da indisciplina dos alunos, situação bastante demarcada pelos iniciantes egressos do PIBID participantes da pesquisa, os quais se reconhecem desafiados para lidar com tais situações. Eles assim ponderaram:

A docência é uma experiência que, de modo indiscutivel, dentro da sala de aula, o professor deve ministrar o conteúdo e principalmente disciplinar o aluno. 0 profissional, infelizmente, perde tempo, desgasta-se até emocionalmente com alunos que vão à escola por obrigação, dificultando, assim, o trabalho do professor. Embora a escola apoie o professor, é trabalhoso e cansativo exigir do aluno em todas as aulas o comportamento. Portanto, o que tenho a destacar como profissional iniciante é a falta de disciplina e educação dos discentes. (Professor Iniciante E).

A indisciplina dos alunos e a dificuldade de concentração é a minha maior dificuldade em sala de aula. (Professor Iniciante F).

As dificuldades em lidar com adolescentes, não só no início da docência, mas sempre acontecem imprevistos com eles. (Professor Iniciante G). 
A dificuldade em relação à indisciplina dos alunos, isso é desmotivante e, por vezes, nos faz pensar em desistir. (Professor Iniciante H).

A questão da indisciplina dos alunos me faz querer desistir da profissão... (Professor Iniciante I).

Outro aspecto difícil da docência é lidar com salas de aulas lotadas e com alunos indisciplinados, pois na minha formação não aprendi a contornar tais situações. (Professor Iniciante J).

Os registros em análise chamam atenção para a necessidade de maior apoio aos iniciantes, em particular, no que concerne à gestão disciplinar. Não é demais lembrar o que adverte Cavaco (1991), ao ensinar que o

[...] papel de professor, por si só, não assegura o reconhecimento de sua 'autoridade' perante os alunos no contexto da sala de aula. $\mathrm{Na}$ ausência de apoio institucional e dos pares, e frente a circunstâncias adversas e nas quais precisa 'construir respostas urgentes para as situações complexas que enfrenta', isso pode levar o iniciante a 'reactualizar' experiências vividas como aluno e elaborar esquemas de actuação que rotiniza e que se filiam em modelos tradicionais, esquecendo mesmo de propostas mais inovadoras que teoricamente defendera. (CAVACO, 1991, p. 164).

Ainda sobre esta observação, nos relatos dos professores iniciantes desta pesquisa, a gestão da aula não é, necessariamente, um problema a ser resolvido, mas uma situação que exige constante deliberação do docente; e isso não é fácil, tampouco se aprende nos livros ou solitariamente.

A infraestrutura da escola é fundamental ao desenvolvimento do trabalho do professor, pois, como advertem Hargreaves et al (2002), os professores também são criações de seu local de trabalho. Em sendo assim, e levando em conta o equilíbrio das respostas que indicam concordância (completa e parcial) e discordância (completa e parcial) da afırmação de que a escola oferece infraestrutura física adequada, é lícito dizer que os contextos de atuação dos iniciantes egressos do PIBID tendem a agravar as dificuldades enfrentadas no começo da docência. Por outro lado, declaram que têm acesso aos equipamentos e recursos tecnológicos, bem como aos materiais pedagógicos da escola, uma vez que as afirmações de aquiescência (concordância completa e parcial) preponderam as de discordância (completa e parcial).

No que concerne às condições de trabalho, estes professores mostram-se parcialmente satisfeitos com a carga laboral horária, e destacam que não consideram adequado o número de alunos por turma, identificando-as em seus relatos como 'superlotadas' e restritivas da gestão da aula. Também ressaltam que não estão satisfeitos com o salário, posição predominante entre os respondentes deste estudo no Ceará. 0 depoimento que segue é ilustrativo do posicionamento desses professores:

0 salário é pouco atrativo. Infelizmente o professor em início de carreira tem que se sobrecarregar com muitas turmas e trabalhar os três turnos para tentar ter uma vida decente! Enquanto o 
salário inicial não for digno de um salário de nível superior infelizmente a evasão dos cursos de licenciaturas só tende a aumentar. (Professor Iniciante L).

Em conjunto, a análise desses três aspectos - carga horária de trabalho, número de alunos por turma e salário - evidencia o desagrado dos professores iniciantes com as condições de trabalho que enfrentam nas escolas em que se encontram inseridos, muito embora haja variação na relação entre as respostas de concordância (completa e parcial) e de discordância (completa e parcial) a eles ligadas especificamente. De todo modo, o alerta de Hargreaves et al (2002) reclama atenção por parte da escola e dos gestores educacionais, tendo em vista o desenvolvimento de ações e políticas que fortaleçam tanto a inserção quanto a permanência de novos professores no chão da escola. Ademais, vale lembrar a recomendação da Organização de Cooperação e Desenvolvimento Econômico - OCDE, destacada por André (2012), ao mencionar resultados do relatório "Professores são importantes: atraindo, desenvolvendo e retendo professores eficazes". Segundo a autora,"[...] as políticas para professores devem assegurar que os docentes trabalhem em um ambiente que favoreça seu sucesso", acrescentando que "[...] a preocupação com a desistência de professores competentes tem levado alguns países à adoção de políticas que possam não só atrair, desenvolver e recrutar bons profissionais, mas também criar condições para que os docentes queiram permanecer na profissão”. (p. 115).

No Brasil, a preocupação com o professor iniciante é ainda emergente, seja como tema de pesquisa ou como foco de ações institucionalizadas no âmbito do poder público, conforme mostram os estudos de Davis e outros (2011), bem como o de André (2012). E nos últimos tempos, o PIBID é uma iniciativa atenta a esse segmento, pois tem como objetivo o estímulo à opção pelo magistério desde a formação inicial, privilegiando estudantes dos cursos de licenciatura, futuros professores da educação básica.

Como já assinalado, os professores iniciantes de que tratamos nesta análise são egressos do PIBID no Ceará, os quais fazem uma apreciação bastante positiva da contribuição do programa no início de sua inserção na docência. Referem-se a ele como "um divisor de águas na minha vida e em minha profıssão" (Professor Iniciante M), uma experiência que permitiu "me identificar com a profıssão" (Professor Iniciante N) e assegurou "mais confiança ao assumir a docência” (Professor Iniciante 0). Reconhecem que ter participado do PIBID contribuiu para seu desenvolvimento profissional, destacando que "muitas das práticas observadas atribuí às minhas aulas e as utilizo até hoje”. (Professor Iniciante P). Os registros reforçam a importância de ações de iniciação à docência ainda no contexto da formação inicial, especialmente para que o iniciante se reconheça como professor e se familiarize com os gestos, pensamentos e fazeres característicos do trabalho (GARCÍA, 1999; CAVACO, 1991; NONO; MIZUKAMI, 2006).

0 domínio de conhecimentos, a relação entre tais conhecimentos e a prática cotidiana, a necessidade de deliberar sobre situações não previstas e de criar ou improvisar atividades estimuladoras, bem como de firmar sua autoridade perante os colegas e alunos, são inquietações recorrentes entre esses iniciantes, ao explicitarem as contribuições do programa: 
No início, o lecionar foi difícil, pois era muito jovem, mais parecia ser uma nova colega da turma e do que a professora; precisei ultrapassar a barreira do preconceito da idade e mostrar que possuía o conhecimento e as estratégias de ensino necessárias para uma boa aprendizagem. Parecia que eu estava traçando uma guerra em sala, eram 40 alunos contra mim. $O$ PIBID me auxiliou bastante nesse aspecto, deu-me a segurança necessária para entrar em sala com confiança e não "armada" para uma batalha. Sinto-me, hoje, realizada com a profissão, amo meu trabalho e, principalmente, meus alunos. Minhas aulas se adaptam à necessidade deles e não mais na autoafırmação do deter conhecimento. (Professor Iniciante Q, grifamos).

O PIBID foi de suma importância para minha formação acadêmica e atuação na docência, pois a partir deste programa pude conhecer a realidade da escola através da participação no cotidiano da instituição de ensino. Ensinar não é somente transmitir conteúdos, mas sim, formar e participar ativamente da vida e aprendizagem dos jovens estudantes. 0 programa me permitiu diversificar e analisar outras maneiras de transmitir os temas propostos da biologia de modo diversificado, atrativo e inovador. Além disso, possibilitou a participação em congressos nacionais para exposição de trabalhos desenvolvidos nas escolas participantes do programa. Sem dúvidas, o PIBID é inovador, pioneiro na formação de licenciandos e comprovadamente eficiente para tornar licenciados prontos para seguir a carreira de docentes qualificados na educação brasileira. (Professor Iniciante R, grifamos).

Os grifos realçam as contribuições identificadas pelos professores iniciantes cearenses egressos do PIBID aos quais vimos nos referindo, destacando desde conhecer a realidade escolar, ultrapassar barreiras decorrentes de ser jovem, aprender a lidar com os desafios da sala de aula e reconhecer que a docência requer conhecimento específico. Ao mesmo tempo, os relatos, em particular os excertos transcritos, permitem entender porque Vaillant e García (2012, p. 124) definiram a inserção na docência como "[...] um período intensivo de tensões e aprendizagens, em contextos geralmente desconhecidos e durante o qual essa categoria de professores deve adquirir conhecimento profissional, além de conseguirem manter certo equilíbrio pessoal".

Conhecer o contexto de trabalho, compreender como funciona, entender a cultura profissional e institucional ali reinante - tudo isso leva tempo e é exigente emocionalmente, mas central na constituição de professores qualificados, tal como pondera o Professor Iniciante R. Com efeito, o contato direto, sistemático e continuado com a escola destaca-se nos depoimentos sobre o PIBID como um diferencial.

0 reconhecimento de que ensinar pode até parecer fácil, tal como exprimem Lüdke e Boing (2012), mas que longe está de ser uma atividade que pode ser improvisada, por isso mesmo requer conhecimento especializado, também é nítido entre esses professores que começam sua vida profissional, conforme ilustram os dois depoimentos supra mencionados.

Ser jovem, expressão em geral associada a imaturidade e falta de capacidade para decidir, torna ainda mais delicada a condição de professor iniciante, conforme registrado pelo Professor Iniciante Q. Embora se refira ao contexto da sala de aula, ao desafio de firmar sua autoridade como docente perante os alunos, essa resistência também se faz notar entre os colegas da escola, conforme assinalado anteriormente. Nessas situações, 
pelo que deixam entrever os comentários dos investigados deste estudo, o domínio do conhecimento profissional, especialmente o disciplinar e o didático-pedagógico, serve de ancoragem que possibilita sustentar a posição de docente perante os colegas e discentes.

Enfim, a marca da sobrevivência, da descoberta e do enfrentamento de desafios da sala de aula e da escola matiza os percursos vivenciados nos primeiros anos de docência de professores iniciantes egressos do PIBID, os quais são enfáticos em distinguir que a participação nessa experiência foi decisiva para ser professor, pois, ao fortalecer seu conhecimento profissional, consideram que os qualificou para enfrentar os desafios do ensinar; em suma, uma experiência que alterou o curso de suas vidas e de sua inserção no magistério.

\section{Perspectivas dos professores iniciantes sobre a permanência ou não na docência}

Dos professores iniciantes, de que falamos neste artigo, responderam à pesquisa de levantamento 199. Desses, um contingente de 163 (81,90\%) afirmou que pretende permanecer na docência. As justificativas, nesse caso, aludem à identificação e gosto pela docência, bem como a uma relevância social dessa atividade.

0 gosto e a identificação com a docência são assim, por eles, expressos:

Sim. É uma área de atuação que me encanta. Meu interesse, embora os percalços continuem. (Professor Iniciante S).

Sim, porque a docência me satisfaz. (Professor Iniciante T).

Foi a profissão que escolhi e apesar do pouco reconhecimento, acredito que dias melhores virão, quando este profissional terá o respeito da sociedade! (Professor Iniciante U).

Sim. Me identifiquei com a profissão, tenho prazer em meu trabalho. (Professor Iniciante V).

Sim, pois gosto muito e me identifico como professora. (Professor Iniciante X).

Cavaco (1991, p. 166) refere-se ao gosto pela profissão, destacando-o como importante elemento que, nos primeiros tempos, facilita "[...] a apropriação criticamente reflectida das diversas competências profissionais”. Ter afınidade, gostar do que faz, é um componente que impulsiona e motiva a busca por aprender, sobretudo em um trabalho complexo como a docência.

Outro argumento apresentado para justificar o interesse em permanecer na docência reporta-se ao reconhecimento de sua relevância social, expressa no entendimento de que, "apesar das imensas dificuldades, ainda é um dos meios mais eficazes de mudar o nosso meio" (Professor Iniciante Z), assim como na crença de que "a aquisição, análise e produção de conhecimentos favorece uma visão de mundo mais rica, que por sua vez, possibilita a formação de pessoas mais éticas e capazes de produzir mudanças em nossa realidade" 
(Professor Iniciante K). 0 desejo de contribuir para mudanças na sociedade e de 'fazer a diferença' na vida dos alunos, o que evidencia uma significativa associação à natureza ética da função docente ("ser professor é muito mais que um emprego para mim; sinto como um dever social e sinto prazer em cumprir esse dever" - Professor Iniciante W), dá o tom às justificativas expressas pelos investigados. Vale lembrar, retomando as formulações de Contreras (2002), que o "compromisso com a comunidade" é um componente decisivo no modo como esses professores delineiam seu modo de ser e estar na profissão.

Entre os iniciantes que manifestaram dúvida em relação à permanência na atividade professoral, nota-se, sobretudo, o peso de uma carreira "pouco atrativa", com baixos salários, agravada pelo crescimento da indisciplina no contexto escolar. Argumentos similares são apresentados por aqueles que afirmaram que não pretendem permanecer no magistério, alegando tratar-se de um trabalho "muito estressante e que se dá muito pouco reconhecimento, tanto financeiro como profissional”. (Professor Iniciante Y).

\section{Considerações finais}

Pressupusemos, de saída, que o fenômeno de "aprender a ensinar" possui fases, e aquela referente aos primeiros anos de magistério é basilar para "[...] configuração das ações profissionais futuras e para a própria permanência na docência”, quando, então, se confrontam "fatores pessoais" e "aspectos profissionais, estruturais e organizacionais" (PAPI; MARTINS, 2010, p. 43-44). A participação no PIBID proporcionou aos egressos deste estudo, durante a formação inicial e a inserção na carreira, um defrontar-se mais construtivo em relação aos dilemas da profissão, o que forneceu elementos, sobretudo, para se reconhecerem capazes de enfrentar desafios, de reinvenções e inovações.

Ingressam na carreira ainda muito jovens e, dada a rarefeita oportunidade de concursos públicos, têm em sua maioria vínculos precários de trabalho. Possivelmente, o que alicerça a busca por continuidade de atuação na escola pública tenha relação com a desmistificação desta como um locus limitado de possibilidades, perspectiva edificada desde sua inserção na escola pública durante as ações do PIBID sob outro prisma: de futuro profissional docente.

Têm suas práticas reconhecidas pelos pares, familiares e também responsáveis pelos alunos, sentem-se satisfeitos com sua atuação, conhecem os seus afazeres e enfrentamentos, lidam bem com todos esses elementos. Esse início de docência menos conturbado, embora haja menção ao choque de realidade, encontra esteio no modelo pedagógico do PIBID, que traz a atuação docente para a baila dos processos formativos. Expresso de outro modo, uma "[...] formação de professores construída dentro da profissão" (NÓVOA, 2009, p. 25), proporcionando aos futuros "ingressantes" conhecimentos sobre a docência em seus contextos.

Predomina entre os professores iniciantes egressos do PIBID intensa identificação com o magistério, exceto por um reduzido grupo que descobre, com essa experiência e a vivência dos primeiros anos de docência, que prefere investir seus esforços em uma profissão que lhes garanta retorno financeiro mais vantajoso. Podemos inferir que o não desejo de permanência na docência não se configura como ausência de identidade com 
a profissão, pois o indício mais forte, presente em suas falas, é de que a questão de uma vida com melhores condições salariais é o que impulsiona para que busquem um trabalho mais bem remunerado.

Desse modo, e considerando as ponderações de Darling-Hammond (2014) evocadas no início deste escrito, não seria inoportuno dizer que os professores iniciantes egressos do PIBID, em particular os do programa no Ceará, mesmo ante as adversidades inerentes à complexidade da docência, se declaram mais bem preparados para encarar os dilemas dos primeiros anos de magistério. Sob esse prisma, reforçam a premissa de que ter mais formação e, principalmente, uma formação articulada ao futuro contexto de trabalho, favorece a aprendizagem da profissão. Evidenciam que encontram no apoio de colegas experientes, dentro e fora da escola, e nos desafios cotidianos da sala de aula oportunidades para aprenderem, as quais possibilitam qualificar sua atuação nos primeiros anos de docência. Esse tempo, aliás, vem sendo vivenciado com maior confiança e convicção da decisão de ser professor e de sua crença de estar mais bem preparado para exercer esse ofício. Em suma, sentem-se plenos na escolha que fizeram.

\section{Referências}

ALARCÃO, Isabel; ROLDÃO, Maria do Céu. Um passo importante no desenvolvimento profissional dos professores: 0 ano de indução. Formação Docente, Belo Horizonte, v. 6, n. 11, p. 109-126, ago./dez. 2014.

ANDRÉ, Marli Eliza Dalmazo Afonso de. Políticas e programas de apoio aos professores iniciantes no Brasil. Cadernos de Pesquisa, São Paulo, v. 42, n. 145, p. 112-129, abr. 2012. Disponível em: http://www. scielo.br/scielo.php?script=sci_arttext\&pid=S0100-15742012000100008\&lng=en\&nrm=iso. Acesso em: 07 dez. 2019.

ANDRÉ, Marli Eliza Dalmazo Afonso de. Professores iniciantes: egressos de programas de iniciação à docência. Revista Brasileira de Educação, Rio de Janeiro, v. 23, e230095, 2018. Disponível em: http:// www.scielo.br/scielo.php?script=sci_arttext\&pid=S1413-24782018000100280\&lng=pt\&nrm=iso. Acesso em: 07 dez. 2019.

ANDRÉ, Marli Eliza Dalmazo Afonso de. Texto contextos e significados: algumas questões na análise de dados qualitativos, Cadernos de Pesquisa, São Paulo, n. 45, p. 66-71, maio, 1983.

APRECE. Documento base do plano estadual de educação do Ceará. Eixo temático -valorização dos profissionais da educação. Fortaleza: [s. n.], 2015. Disponível em: http://aprece.org.br/wp-content/ uploads/2015/05/Documento-Base-PEE-Valorizacao-de-Profissionais-da-Educacao.pdf. Acesso em: 07 dez. 2019.

BRASIL. Decreto $n^{0}$ 7.219, 24 de junho de 2010. Lei que dispõe sobre o Programa Institucional de Bolsa de Iniciação a Docência. Diário Oficial da União, Brasília, DF, 25 jun. 2010. Disponível em: http://www. planalto.gov.br/ccivil_03/_ato2007-2010/2010/decreto/d7219.htm. Acesso em: 07 dez. 2019.

CAVACO, Maria Helena. Ofício do professor: o tempo e as mudanças. In: NÓVOA, António (Org.). Profissão professor. Porto: Porto Editora, 1991. p. 155-191. 
CAVALCANTE, Maria Mikaele da Silva. Permanecer ou evadir da docência? Estudo sobre perspectivas de professores iniciantes egressos do PIBIDUECE. 2018. Dissertação (Mestrado em Educação) - Universidade Estadual do Ceará, Fortaleza, 2018.

CONTRERAS, José. A autonomia de professores. São Paulo: Cortez, 2002.

CRUZ, Giseli Barreto da. Pesquisa COM professores iniciantes: um estudo sobre indução profissional. Rio de Janeiro: UFRJ, 2018. 45 p. Projeto de Pesquisa (CNPq -Edital Universal 2018).

DARLING-HAMMOND, Linda. A importância da formação docente. Cadernos Cenpec, São Paulo, v. 4, n. 2 , p. 230-247, dez. 2014.

DAVIS, Claudia Leme Ferreira et al. Formação continuada de professores: uma análise das modalidades e das práticas em estados e municípios brasileiros: relatórios de pesquisa. São Paulo: Fundação Carlos Chagas, 2011.

FARIAS, Isabel Maria Sabino de. Inovação, mudança e cultura docente. Brasília, DF: Liber Livro, 2006.

FARIAS, Isabel Maria Sabino et al. A docência universitária sob o prisma da integração ensino e pesquisa. Teresina: Edufpi, 2014.

FARIAS, Isabel Maria Sabino; JARDILINO, José Rubens Lima; SILVESTRE, Magali Aparecida (org.). Aprender a ser professor: aportes de pesquisa sobre o PIBID. Jundiaí: Paco, 2015.

FORMOSINHO, João; MACHADO, Joaquim. Professores na escola de massas: novos papéis, nova profissionalidade. In: FORMOSINHO, João; MACHADO, Joaquim (coord.). Formação de professores: aprendizagem profissional e acção docente. Porto: Porto Editora, 2009. p. 143-164.

FREIRE, Paulo. Pedagogia da autonomia: saberes necessários à prática educativa. 36. ed. São Paulo: Paz e Terra, 2007.

GARCÍA, Carlos Marcelo. Formação de professores: para uma mudança educativa. Porto: Porto Editora, 1999.

GATTI, Bernadete Angelina et al. Atratividade da carreira docente no Brasil: relatório final de pesquisa. São Paulo: Fundação Carlos Chagas: Fundação Victor Civita, 2009.

HARGREAVES, Andy; EARL, Lorna; MOORE, Shawn; MANNING, Susan. Aprendendo a mudar: 0 ensino para além dos conteúdos e da padronização. Porto Alegre: Artmed, 2002.

LÜDKE, Menga; BOING, Luiz Alberto. Do trabalho à formação de professores. Cadernos de Pesquisa, São Paulo, v. 42, n. 146, p. 428-451, maio/ago. 2012.

MARCELO, Carlos. A identidade docente: constantes e desafios. Revista Formação Docente, Belo Horizonte, v. 01, n. 01, p. 109-131, ago./dez. 2009.

MARCELO, Carlos. Pesquisa sobre a formação de professores: 0 conhecimento sobre aprender a ensinar. Revista Brasileira de Educação, Rio de Janeiro, n. 9, p. 51-75, set./dez. 1998. 
MIZUKAMI, Maria das Graças Nicoletti. Escola e desenvolvimento profissional da docência. In: GATTI, Bernadete Angelina et al. Por uma política nacional de formação de professores. São Paulo: Edunesp, 2013. p. 23-54.

NONO, Maévi Anabel; MIZUKAMI, Maria das Graças Nicoletti. Processos de formação de professoras iniciantes. Revista Brasileira de Estudos Pedagógicos, Brasília, DF, v. 87, n. 217, p. 382-400, set./dez. 2006.

NóVOA, António. Professores: imagens do futuro presente. Lisboa: Educa, 2009.

PAPI, Silmara de Oliveira; MARTINS, Pura Lúcia Oliver. As pesquisas sobre professores iniciantes: algumas aproximações. Educação em Revista, Belo Horizonte, v. 26, n. 03, p. 39-56, dez. 2010.

STAKE, Robert E. Pesquisa qualitativa: estudando como as coisas funcionam. Porto Alegre: Penso, 2011.

TARDIF, Maurice. Saberes docentes e formação profissional. 17. ed. Petrópolis: Vozes, 2014.

VALLE, Ione Ribeiro. Carreira do magistério: uma escolha profissional deliberada? Revista Brasileira de Estudos Pedagógicos, Brasília, DF, v. 87, n. 216, p. 178-187, maio/ago. 2006.

VAILLANT, Denise; GARCÍA, Carlos Marcelo. Ensinando a ensinar: as quatro etapas de uma aprendizagem. Curitiba: UTFPR, 2012.

YIN. Robert K. Pesquisa qualitativa do início ao fim. Porto Alegre: Penso, 2016.

Recebido em: 19.07.2019

Revisado em: 11.12.2019

Aprovado em: 18.02.2020

Isabel Maria Sabino de Farias é professora associada da Universidade Estadual do Ceará, vinculada ao Centro de Educação e ao Programa de Pós-Graduação em Educação. É líder do grupo de pesquisa Educação, Cultura Escolar e Sociedade (EDUCAS), realizando estudos sobre desenvolvimento profissional docente, inovação e docência. Bolsista de Produtividade em Pesquisa do CNPq - Nível 2.

Silvina Pimentel Silva é professora adjunta do curso de pedagogia e do Programa de PósGraduação em Educação da Universidade Estadual do Ceará. É pesquisadora e membro do grupo de pesquisa Educação, Cultura Escolar e Sociedade (EDUCAS), onde investiga sobre formação de professores e a relação ensino e pesquisa.

Nilson de Souza Cardoso é professor assistente da Universidade Estadual do Ceará, vinculado ao curso de licenciatura em ciências biológicas, no Campus Crateús e ao mestrado profissional em ensino de biologia em rede nacional (PROFBIO). É pesquisador e membro do grupo de pesquisa Educação, Cultura Escolar e Sociedade (EDUCAS), onde investiga sobre formação de professores da área de ciências da natureza e sobre as políticas de formação inicial, com ênfase naquelas promovidas pela CAPES. 